\title{
Versican in the Developing Brain: Lamina-Specific Expression in Interneuronal Subsets and Role in Presynaptic Maturation
}

\author{
Masahito Yamagata and Joshua R. Sanes \\ Department of Molecular and Cellular Biology, Harvard University, Cambridge, Massachusetts 02138
}

\begin{abstract}
Chondroitin sulfate proteoglycans (CSPGs) of the extracellular matrix help stabilize synaptic connections in the postnatal brain and impede regeneration after injury. Here, we show that a CSPG of the lectican family, versican, also promotes presynaptic maturation in the developing brain. In the embryonic chick optic tectum, versican is expressed selectively by subsets of interneurons confined to the retinorecipient laminae, in which retinal axons arborize and form synapses. It is a major receptor for the Vicia villosa $\mathrm{B}_{4}$ lectin (VVA), shown previously to inhibit invasion of the retinorecipient lamina by retinal axons (Inoue and Sanes, 1997). In vitro, versican promotes enlargement of presynaptic varicosities in retinal axons. Depletion of versican in ovo, by RNA interference, results in retinal arbors with smaller than normal varicosities. We propose that versican provides a lamina-specific cue for presynaptic maturation and discuss the related but distinct effects of versican depletion and VVA blockade.
\end{abstract}

Key words: optic tectum; versican; lectican; proteoglycan; synapse formation; VVA- $\mathrm{B}_{4}$

\section{Introduction}

The vertebrate CNS was long believed to bear little, if any, extracellular matrix (ECM) and to lack the molecular species that comprise the ECM of non-neural tissues. Over the past 15 years, however, this view has changed, and it is now clear that the CNS bears a rich matrix in both embryos and adults and that its components play numerous roles in neuronal development, function, and plasticity (for review, see Sanes, 1993; Bandtlow and Zimmermann, 2000; Yamaguchi, 2000; Dityatev and Schachner, 2003).

Prominent components of the ECM of the brain are chondroitin sulfate proteoglycans (CSPGs) of the "lectican" family: aggrecan, brevican, neurocan, and versican (Bignami et al., 1993; Matsui et al., 1998; Milev et al., 1998; Schmalfeldt et al., 1998; Hagihara et al., 1999; Yamaguchi, 2000; Matthews et al., 2002; Popp et al., 2003, 2004). Recent studies have implicated lecticans in two phenomena in the postnatal brain. First, they are components of "perineuronal nets" that ensheath many neurons (Celio et al., 1998). These nets appear postnatally, around the time that synaptic connections stabilize, and they appear to participate in the stabilization process (Hockfield et al., 1990; Dityatev and Schachner, 2003). Second, their expression by glial cells is upregulated after neural injury, and they are incorporated into glial

Received May 17, 2005; revised July 28, 2005; accepted July 31, 2005.

This work was supported by a grant from the National Institutes of Health (J.R.S.). We thank Steve Hughes for RCAS vectors, John Majors for valuable discussion on designing retroviral vectors, Koji Kimata and Tamayuki Shinomura for versican CDNAs, Paul Linser for antibody to glutamine synthetase, Joshua Weiner for comments, and Jeanette Cunningham for technical assistance.

Correspondence should be addressed to Dr. Joshua R. Sanes, Department of Molecular and Cellular Biology, Harvard University, 7 Divinity Avenue, Cambridge, MA 02138. E-mail: sanesj@mcb.harvard.edu.

D01:10.1523/JNEUROSCI.1976-05.2005

Copyright $\odot 2005$ Society for Neuroscience $\quad$ 0270-6474/05/258457-11\$15.00/0 scars that appear to hinder regeneration (Asher et al., 2002). In support of the involvement of CSPGs in these processes, infusion of chondroitinase into the CNS restores synaptic plasticity to mature animals (Pizzorusso et al., 2002; Tropea et al., 2003; Berardi et al., 2004) and promotes regeneration of central axons after injury (Moon et al., 2001; Bradbury et al., 2002). In addition, because upregulation of lecticans after neural injury is most prominent in regions of inflammation or blood-brain barrier breakdown, it has been suggested that they play a neuroprotective role in limiting secondary injury (Rhodes and Fawcett, 2004).

Lecticans are present in the embryonic as well as the postnatal brain (Margolis and Margolis, 1993; Bandtlow and Zimmermann, 2000; Silver and Miller, 2004), and they exert a striking inhibitory effect on neurite outgrowth in vitro (Schmalfeldt et al., 2000; Schweigreiter et al., 2004). In contrast to growing knowledge about roles of lecticans in the postnatal brain, however, little is known about their roles in embryonic neural development. Here, we provide evidence that one lectican, versican, promotes presynaptic differentiation. Our study was motivated by our previous observation that a plant lectin, Vicia villosa agglutinin- $\mathrm{B}_{4}$ (VVA), selectively stains the retinorecipient laminae of the tectum in which retinal ganglion cells (RGCs) form their terminal arbors (Yamagata et al., 1995). VVA stains the retinorecipient laminae both before entry of RGC axons and during the embryonic period when they are forming synapses. Moreover, application of VVA to developing tecta impedes ingrowth of retinal axons (Inoue and Sanes, 1997). We began the present study by attempting to identify the tectal molecules recognized by VVA. We found that versican (also known as PG-M) is the major VVA ligand in the retinorecipient laminas. Based on this result, we analyzed the expression of versican in the tectum, reassessed its effects on retinal neurites in vitro, and used RNA interference 
(RNAi) to test its function in vivo. We report here that versican is expressed by a heterogeneous subset of neurons in the retinorecipient laminae and that it promotes maturation of presynaptic varicosities within the retinal arbors that innervate those neurons.

\section{Materials and Methods}

Isolation and characterization of VVA-binding molecules from the tectum. To identify VVA-reactive species, one embryonic day 14 (E14) tectum was cultured in ${ }^{35} \mathrm{~S}$-methionine-containing DMEM and $10 \%$ fetal calf serum in $5 \% \mathrm{CO}_{2}$ for $15 \mathrm{~h}$ and homogenized with $5 \mathrm{ml}$ of NET buffer (0.5\% NP-40, $0.15 \mathrm{~m} \mathrm{NaCl}, 10 \mathrm{~mm}$ EDTA, and $50 \mathrm{~mm}$ Tris-HCl, $\mathrm{pH}$ 7.4). The lysate was centrifuged at $10,000 \times g$, and the supernatant was incubated with VVA-coupled agarose or unconjugated Sepharose 4B (Sigma, St. Louis, MO) at $4^{\circ} \mathrm{C}$ for $15 \mathrm{~h}$. The columns were washed with NET buffer and eluted with $50 \mathrm{~mm}$ Tris- $\mathrm{HCl}, \mathrm{pH} 7.4$, plus $10 \mathrm{~mm}$ $\mathrm{N}$-acetylgalactosamine (GalNAc) or $\mathrm{N}$-acetylglucosamine (GlcNac). All solutions were supplemented with protease inhibitors (Complete; Roche, Indianapolis, IN). Eluted material was precipitated with 3 vol of $95 \%$ ethanol containing $1.3 \%$ potassium acetate and analyzed by SDSPAGE and fluorography (Amplify; Amersham Biosciences, Piscataway, $\mathrm{NJ})$, using either $5 \%$ or $5-15 \%$ gradient gels.

To isolate VVA-binding molecules, 300 E14-E15 tecta were homogenized with NMT buffer $\left(0.5 \% \mathrm{NP}-40,0.15 \mathrm{M} \mathrm{NaCl}, 10 \mathrm{mM} \mathrm{MgCl}_{2}\right.$, and 50 $\mathrm{mm}$ Tris-HCl, $\mathrm{pH} 7.4)$ and centrifuged at $10,000 \times g$. The supernatant was incubated with Sepharose $4 \mathrm{~B}$ to remove agarose-binding molecules and applied to a $5 \mathrm{ml} \mathrm{VVA-agarose}$ column. The column was washed with NMT buffer and eluted with $10 \mathrm{~mm}$ GalNAc and $50 \mathrm{~mm}$ Tris- $\mathrm{HCl}$, $\mathrm{pH}$ 7.4. The chromatographic fractions were assayed by applying $10 \mu \mathrm{l}$ aliquots to a nitrocellulose membrane and using biotinylated VVA and horseradish peroxidase-conjugated streptavidin (Vector Laboratories, Burlingame, CA) to detect VVA-binding moieties (dot blotting). Unabsorbed material was reapplied to the column twice to increase the yield of VVA-binding material. Eluate fractions containing VVA-binding material were combined, concentrated by ethanol precipitation, and subjected to gel electrophoresis. A Coomassie blue-stained band centered at $\sim 500$ $\mathrm{kDa}(\sim 0.5 \mu \mathrm{g}$ of protein) was excised, subjected to in-gel tryptic digestion, and analyzed by mass spectroscopy [matrix-assisted desorption ionization-mass spectrometry (MS) and nanospray MS/MS) at the Keck Facility at Yale University (New Haven, CT).

Proteoglycans were purified from 200 E14-E15 tecta by the method of Hascall et al. (1994). Tecta were homogenized in $20 \mathrm{ml}$ of $4 \mathrm{M}$ guanidium chloride and $50 \mathrm{~mm}$ Tris- $\mathrm{HCl}, \mathrm{pH}$ 7.5, supplemented with protease inhibitors (Complete; Roche). The homogenate was centrifuged at $15,000 \times \mathrm{g}$ to remove debris, $\mathrm{CsCl}$ was added to a density of $1.35 \mathrm{~g} / \mathrm{ml}$, and material was fractionated by two rounds of isopycnic centrifugation. Material between 1.45 and $1.50 \mathrm{~g} / \mathrm{ml}$ was collected in both rounds and dialyzed against water. Staining with Alcian blue revealed material that barely entered the separation gel (probably $>1000 \mathrm{kDa}$ ) and transferred poorly, if at all, to polyvinylidene difluoride membranes (NEN, Boston, $\mathrm{MA}$ ). This material was analyzed by digestion with protease-free chondroitinase ABC (Seikagaku, Tokyo, Japan) and staining with Coomassie blue or immunoblotting with an antibody that reacts with carbohydrates generated by chondroitinase $\mathrm{ABC}$ treatment (anti-chondroitin sulfate stub antibody 1B5) (Caterson et al., 1985). In the digest, the major Coomassie blue-positive band migrated at $M_{\mathrm{r}} \sim 500,000$ and corresponded to the only major 1B5-positive band, indicating that CSPGs were the major components of these fractions.

Histology. Tissue was fixed with $4 \%$ paraformaldehyde, sectioned at 20 $\mu \mathrm{m}$ in a cryostat, and stained with antibodies as described by Yamagata et al. (1995). The antibodies used in this study were as follows: glutamine synthetase (a gift from Paul Linser, University of Florida, Gainesville, FL) (Linser and Moscona, 1981); anti-retroviral gag protein (AMV3C2), SV2, and anti-synaptotagmin (mab 48; all from Developmental Studies Hybridoma Bank, Iowa City, IA); anti-postsynaptic density-95 (PSD-95; Affinity Bioreagents, Golden, CO); anti-gephyrin (clone 7a; Connex, Martinsried, Germany); and anti-L1/NgCAM antibody H23 (produced in our laboratory) (Herman et al., 1993).
In situ hybridization was performed as described by Yamagata et al. (2002) using 5-bromo-4-chloro-3-indolyl-phosphate/nitro blue tetrazolium or the tyramide signal amplification system (TSA Plus system; PerkinElmer, Wellesley, MA).

Retinal arbors were labeled by application of DiI to the optic tract, as described by Yamagata and Sanes (1995a).

Images were obtained on an Axioplan (Zeiss, Thornwood, NY) and processed by Adobe Photoshop or analyzed using Image J or Volocity (Improvision, Lexington, MA).

Retroviral vectors for RNAi. To suppress versican expression in ovo, we modified replication-competent RCAS-BP vectors (Hughes et al., 1987) to express small duplex RNA sequences from an H1 RNA polymerase III promoter (Brummelkamp et al., 2002). The vector design is shown in Figure $3 a$. The unique ClaI site in the RCAS-BP vectors was disrupted by digestion, treatment with Klenow, and religation. A new ClaI site was then created in the $3^{\prime}$ long terminal repeat (LTR), three bases after an integrase recognition sequence (ATGTAGTC) (Mumm and Grandgenett, 1991), generating RCAT-BP vectors.

To insert potential interfering sequences into the RCAT-BP vectors, the H1 promoter, and associated BglII-HindIII cloning sites, obtained from pSUPER (OligoEngine, Seattle, WA), were cloned into the adaptor plasmid Cla12 (Hughes et al., 1987) to generate a modified adaptor plasmid, ClaH1. Oligonucleotides corresponding to small duplex RNAs were cloned into the BglII-HindIII site of ClaH1. Finally, the ClaI fragment from the modified ClaH1 was cloned into the ClaI site of the RCAT-BP vectors.

In initial tests of our vectors, we used the adaptor plasmids to insert sequences corresponding to green fluorescent protein (GFP) into the ClaI site of RCAT-BP or RCAS-BP. The sequence used was CCACTACCTGAGCACCCA. The plasmids were transected into QT-6 cells (American Type Culture Collection, Manassas, VA), and virions in the supernatant were used to infect cells of a QT-6 line that stably expressed GFP. Both RCAT-BP(GFP-RNAi) and RCAS-BP(GFP-RNAi) suppressed GFP expression, but the RCAT-BP virus was more effective than the RCAS-BP virus. Orientation of the ClaH1-derived cassette in the retroviral vector did not detectably affect RNAi; the reversed orientation was used thereafter.

Based on these results, we used RNAi prediction programs (SVM RNAi; Chang Bioscience, Castro Valley, CA) to design seven sequences corresponding to versican RNA. Each was cloned into RCAT-BP and tested in chick embryonic fibroblasts, which express endogenous versican; the fibroblasts were stained with a monoclonal antibody to versican (Yamagata et al., 1993a,b). A vector containing the sequence CACATGCAAGATGAAGTTG suppressed versican expression most effectively and was used thereafter.

To introduce the retroviral vectors into chick embryos, we generated RCAT-BP plasmids bearing two different envelope protein genes (A and B) (Hughes et al., 1987; Homburger and Fekete, 1996) and cotransfected them by in ovo microelectroporation (Momose et al., 1999) into the mesencephalon at Hamburger-Hamilton stage 11-12 (E2), using an ECM830 device (BTX, Holliston, MA). In this protocol, initially transfected cells generate virions that can then infect other cells. Incorporation of RCAT vectors, by transfection or infection, was monitored by staining tissue for the Gag protein, encoded by the viral gag gene. Significant gag expression was observed in tecta of $\sim 50 \%$ of electroporated embryos. Of these, $\sim 20 \%$ showed expression in nearly all tectal cells; the data shown here are from this heavily infected subset. In contrast, few retinal cells were gag positive.

Our method includes two improvements over a previous method for retrovirus-mediated RNAi in chick embryos (Kawakami et al., 2003). First, placing the duplex RNA-expressing transcription unit in the LTR (in RCAT-BP) introduces two copies of the cassette into each cell by a single integration event (because of duplication of the $3^{\prime}$ LTR during the reverse transcription that precedes integration), whereas only one is introduced in RCAS-BP. Second, the use of two distinct viral subgroups of envelope protein allows each cell to be doubly infected (Homburger and Fekete, 1996).

Neuronal cultures on patterned substrates. To assess responses of retinal neurons to CSPGs, we generated cultures in which retinal axons extend- 
a)
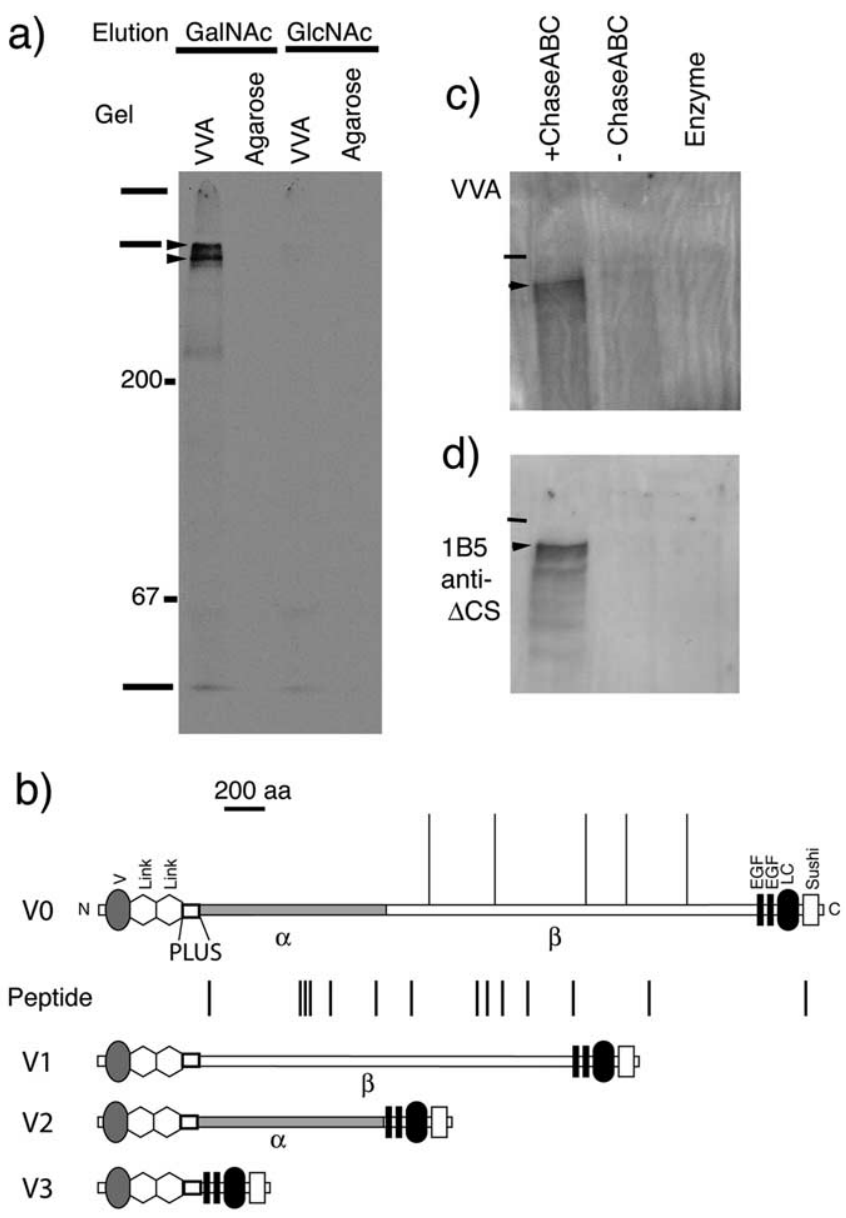

Figure 1. Identification of versican as a VVA ligand. $\boldsymbol{a}$, Lysates from $\left[{ }^{35} \mathrm{~S}\right]$ methioninelabeled E14 tecta were incubated with agarose or VVA-agarose, washed, and eluted with $10 \mathrm{~mm}$ GalNAc or GICNAc. The eluted material was fractionated on a 5\% SDS gel that was then developed fluorographically. The major bands migrated at $\sim 500$ and $>800 \mathrm{kDa}$ (arrowheads). The lines on left indicate the top and bottom of the stacking gel and dye front. $\boldsymbol{b}$, Structure of alternatively spiced forms of versican: V0, V1, V2, and V3. The vertical lines below V0 show the location of 14 versican-derived peptides identified by MS. V, Immunoglobulin V domain; Link, link protein homology domain; PLUS, $\alpha$ and $\beta$ alternatively spliced segments; EGF, epidermal growth factor-like domain; LC, lectin C-type domain; Sushi, complement control protein domain. The vertical bars above V0 show the sites at which glycosaminoglycan chains can be added. c, Proteoglycans isolated from optic tecta were digested with chondroitinase $A B C$ (+ChaseABC), fractionated, and probed with VVA. - ChaseABC, Untreated proteoglycans; Enzyme, chondroitinase $\mathrm{ABC}$ alone. $\boldsymbol{d}$, A duplicate immunoblot probed with monoclonal antibody $1 B 5$, which recognizes the "stub" carbohydrate (CS) produced by chondroitinase $A B C$ digestion. Both VVA and $1 B 5$ recognize a $\sim 500 \mathrm{kDa}$ band (arrowhead).

ing on a growth-promoting substrate (laminin plus poly-L-lysine) encountered patches in which CSPG was present along with the laminin/ poly-L-lysine. Three methods were used to generate patterned substrates. In the first method, small spots of the purified tectal CSPG fraction described above were sprayed onto glass coverslips using a biolistic device (Helios gene gun; Bio-Rad, Hercules, CA), essentially as described by Kummer et al. (2002). The gene gun was loaded with $0.05 \mu \mathrm{g}$ of CSPG plus $1 \mu \mathrm{g}$ of fluorescein isothiocyanate-coupled bovine serum albumin (BSA) in $10 \mu \mathrm{l}$ of distilled water. In the second method, $1 \mu \mathrm{l}$ drops of the same solution were applied manually to glass coverslips. In both cases, the coverslips were uniformly coated with $1 \mu \mathrm{g} / \mathrm{ml} \mathrm{laminin} \mathrm{(Invitrogen,}$ Carlsbad, CA) plus $10 \mu \mathrm{g} / \mathrm{ml}$ poly-L-lysine (Sigma) before CSPG was applied. In the third method, stripes of CSPG were applied atop laminin/ poly-L-lysine-coated Whatman (Maidstone, UK) 110605 membranes, using the device described by Walter et al. (1987). In this case, $0.05 \mu \mathrm{g}$ of CSPG and $1 \mu \mathrm{g}$ of fluorescein-BSA were diluted in $150 \mu \mathrm{l}$ of PBS; fluorescein-BSA alone was used as a control.
Retinal explants were prepared as described by Yamagata and Sanes (1995a) based on the method of Drazba and Lemmon (1990). Briefly, E7 chick retinas were spread photoreceptor side down on a concanavalin A-coated black nitocellulose membrane (Millipore, Billerica, MA) and sliced with a Sorvall (Newtown, CT) TC-2 tissue sectioner. Slices were cultured on the patterned substrates for $7 \mathrm{~d}$ in Neurobasal (Invitrogen) medium supplemented with $10 \%$ fetal bovine serum, $1 \mathrm{ng} / \mathrm{ml}$ brainderived neurotrophic factor (Promega, Madison, WI), and 4\% B27 supplement (Invitrogen). For analysis, cultures were fixed and stained with antibodies to SV2 or L1/NgCAM.

\section{Results}

\section{Proteoglycans as VVA ligands}

The lectin VVA, which binds to GalNAc-terminated carbohydrates, selectively stains the retinorecipient laminae in the chick optic tectum (Yamagata et al., 1995). Staining by VVA is blocked by free GalNAc but not by the closely related sugar GlcNAc (Scott et al., 1988; Piller et al., 1990; Yamagata et al., 1995). Other lectins that recognize GalNAc-terminated carbohydrates stained in a similar pattern, whereas lectins that recognize other sugars did not stain the retinorecipient laminae selectively (Yamagata et al., 1995; Miskevich, 1999). To seek tectal molecules recognized by VVA, we applied metabolically labeled tectal lysates to VVAagarose and sought material eluted by GalNAc- but not by GlcNAc-containing buffers. Gel electrophoresis and fluorography revealed two closely spaced bands in the GalNAc eluate: one of $\sim 500 \mathrm{kDa}$ and one so large that it barely entered separation gels (>800 kDa) (Fig. 1a). Neither band was eluted from VVAagarose by GlcNAc or from unconjugated agarose by either GalNAc or GlcNAc. No other specifically eluted bands of $>9 \mathrm{kDa}$ were detected consistently. A band at $\sim 250 \mathrm{kDa}$ is visible in Figure $1 a$, but it was not present in other preparations and was not studied further.

To identify the large VVA-reactive species, we purified material from 300 tecta using VVA-agarose. The major band was excised from the gel, trypsinized, and subjected to MS. Twenty-four fragments were identified, all of which were derived from proteoglycans: 14 (58\%) from versican (Fig. 1b), 6 (25\%) from agrin, and $4(17 \%)$ from aggrecan. This result suggests that the main VVA ligands are proteoglycans and that a predominant VVAreactive proteoglycan is versican.

To test this idea, we isolated proteoglycans from tecta (see Materials and Methods) and asked whether VVA bound to them after electrophoretic transfer to a membrane. The purified proteoglycans were large $(>800 \mathrm{kDa})$ and transferred poorly to the membrane, so reactivity to VVA was difficult to assess. We therefore treated the material with chondroitinase $\mathrm{ABC}$, which removes the majority of chondroitin sulfate chains from CSPGs. The digest contained a single major band of $\sim 500 \mathrm{kDa}$, which reacted strongly with an antibody to the residual sugars of CSPGs (1B5) (Caterson et al., 1985) and with VVA (Fig. 1c). From these results, we conclude that VVA binds to tectal CSPGs but not uniquely to their GalNAc-containing glycosaminoglycan moieties. Consistent with this idea, VVA does not bind to isolated glycosaminoglycans, including chondroitin, chondroitin sulfate, and heparan sulfate (Scott et al., 1988). Instead, VVA may bind to other GalNAc residues N- or O-linked to the proteoglycans. The $\sim 500 \mathrm{kDa}$ band isolated from tectal lysates on VVA-agarose (Fig. $1 a$ ) is likely to comprise proteoglycan core proteins that bear few or short glycosaminoglycan chains, either because of heterogeneity in vivo (Schwartz, 2000) or because of deglycosylation during purification. 


\section{Versican as a VVA ligand}

We next used in situ hybridization to ask whether genes encoding versican or the other proteoglycans isolated on VVA-agarose, aggrecan and agrin, are expressed in the retinorecipient laminae of the tectum, which is selectively stained by VVA (Fig. $2 a$ ). Because versican and aggrecan are structurally related lecticans, we also assessed expression of the other two members of this family, brevican and neurocan (Yamaguchi, 2000; Wight, 2002). Of these five proteoglycans, only versican was selectively expressed in the retinorecipient laminae (Fig. $2 b$ ). Versican-positive cells were detected in the retinorecipient laminae by E10, increased in number until $\sim$ E14, and decreased in intensity over the next several days, but they were clearly detectable at least until hatching, the latest stage examined (data not shown).

In contrast, agrin mRNA was expressed by cells in all of the laminae (Fig. 2c), aggrecan and brevican mRNAs were concentrated in the ventricular zone (Fig. $2 d, e$ ), and neurocan mRNA was concentrated in deep (non-retinorecipient) laminae (Fig. $2 f$ ). Likewise, antibodies to agrin and chondroitin sulfate stained the tectum diffusely, and antibodies to aggrecan stained the stratum opticum and ventricular surface somewhat selectively (Yamagata et al., 1995) (Fig. 2g). These expression patterns are consistent with the idea that the major tectal VVA-binding proteoglycan is versican. We do not know whether aggrecan and agrin are also VVA ligands or whether they coaggregate with versican (for example, via their association with hyaluronan) (Kimata et al., 1986) and therefore were copurified with versican on VVA-agarose.

Alternative splicing of the versican gene generates several isoforms that are expressed in distinct spatiotemporal patterns (Shinomura et al., 1993; Wight, 2002). We used probes to two alternatively spliced segments ( $\alpha$ and $\beta$ ) (Fig. $1 b$ ) to determine which isoforms are expressed in the tectum. The $\alpha$ segment is present in $\mathrm{V} 2$ but not in $\mathrm{V} 1$, the $\beta$ segment is present in $\mathrm{V} 1$ but not in $\mathrm{V} 2$, both are present in V0, and neither is present in V3. Indistinguishable patterns were observed with $\alpha$ and $\beta$ probes, suggesting either that the predominant form was V0 or that V1 and V2 were extensively coexpressed (data not shown). The molecular weight of the predominant band $(\sim 500 \mathrm{kDa})$ (Fig. 1 c) is most similar to that expected for $\mathrm{V} 0$, and this band contained peptides derived from both $\alpha$ and $\beta$ segments, suggesting that V0 is the predominant form in the tectum. We also used reverse transcription-PCR to ask whether the chicken PLUS exon (Zako et al., 1997) (Fig. 1b) was present in tectal versican RNA; all detectable versican transcripts contained the PLUS exon (data not shown).

To critically test the idea that versican is the major VVAbinding molecule in the retinorecipient laminae, we asked whether VVA bound to retinorecipient laminae of tecta that had been selectively depleted of versican. For this purpose, we improved a previously reported method for expressing a small duplex RNA from a replication-competent avian retroviral vector (Fig. 3a) (see Materials and Methods). Nearly all cells were infected in tecta treated with control or versican-directed vectors (Fig. $3 c^{\prime}, d^{\prime}$ ). Infection with a versican-directed vector shown initially to be effective in cultured cells (see Materials and Methods) markedly reduced levels of the VVA-binding, $\sim 500 \mathrm{kDa}$ band (Fig. $3 b$ ) and markedly reduced staining of retinorecipient laminae by VVA (Fig. $3 d$ ). The effects of the RNAi were specific in that other markers of retinorecipient laminas were unaffected (Fig. $3 e-h$ and data not shown) and infection with a control vector did not affect VVA staining (Fig. 3c). This result provides direct evidence that versican is the major VVA ligand in the retinorecipient laminae.
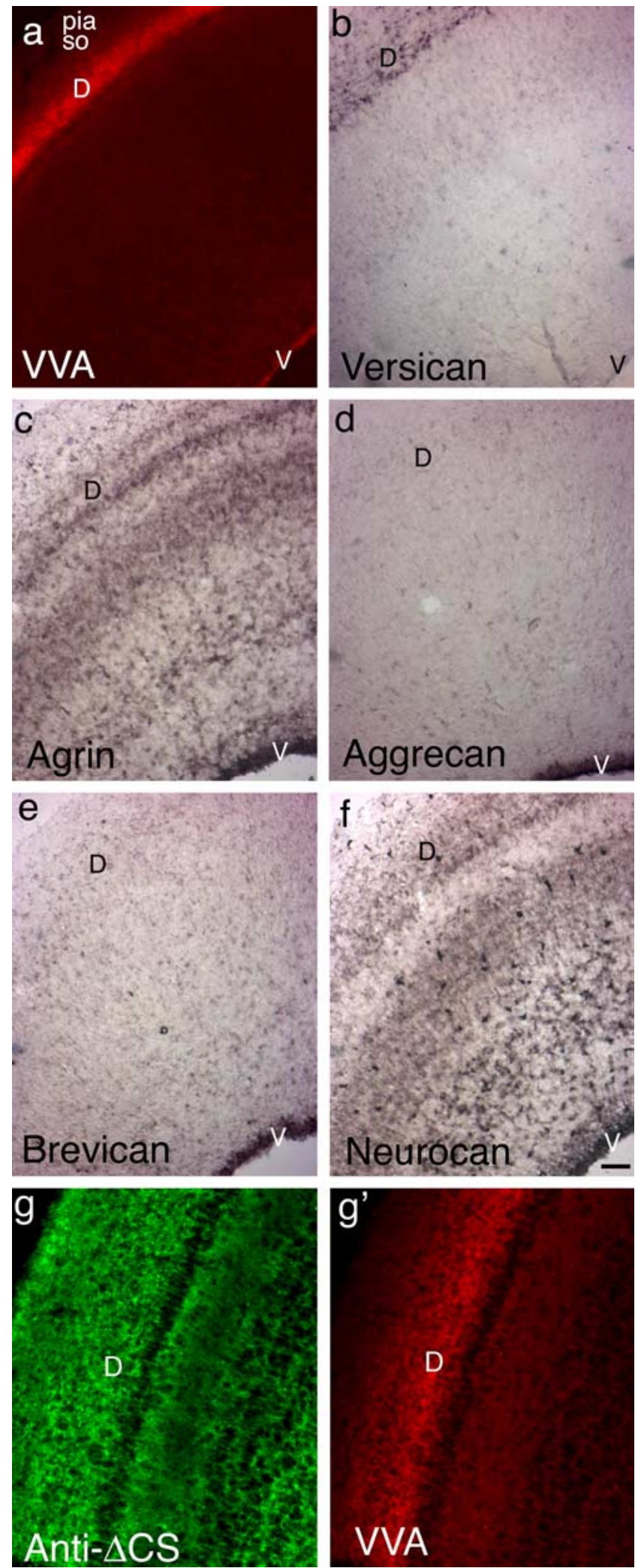

Figure 2. Expression of proteoglycans in the optic tectum. Sections of the E14 optic tectum were stained with VVA $(\boldsymbol{a})$ or hybridized with probes for the indicated proteoglycans $(\boldsymbol{b}-\boldsymbol{f})$. Versican is selectively expressed in the retinorecipient laminae $(\boldsymbol{b})$, agrin and neurocan are broadly expressed $(\boldsymbol{c}, \boldsymbol{f})$, and aggrecan and brevican are selectively expressed by cells that line the ventricle $(\boldsymbol{d}, \boldsymbol{e}) . \boldsymbol{g}$, Chondrotin sulfate (CS), stained with anti-stub antibody after chondroitinase digestion (see Fig. 1 legend), is more broadly distributed than VVA-reactive material $\left(\boldsymbol{g}^{\prime}\right)$. Note that VVA staining survives chondroitinase digestion. D, Layer SGFS-D; V, ventricular surface. so, Stratum opticum. Scale bar: (in $\boldsymbol{f}$ ) $\boldsymbol{a}-\boldsymbol{f}, 50 \mu \mathrm{m} ; \boldsymbol{g}, 25 \mu \mathrm{m}$. 

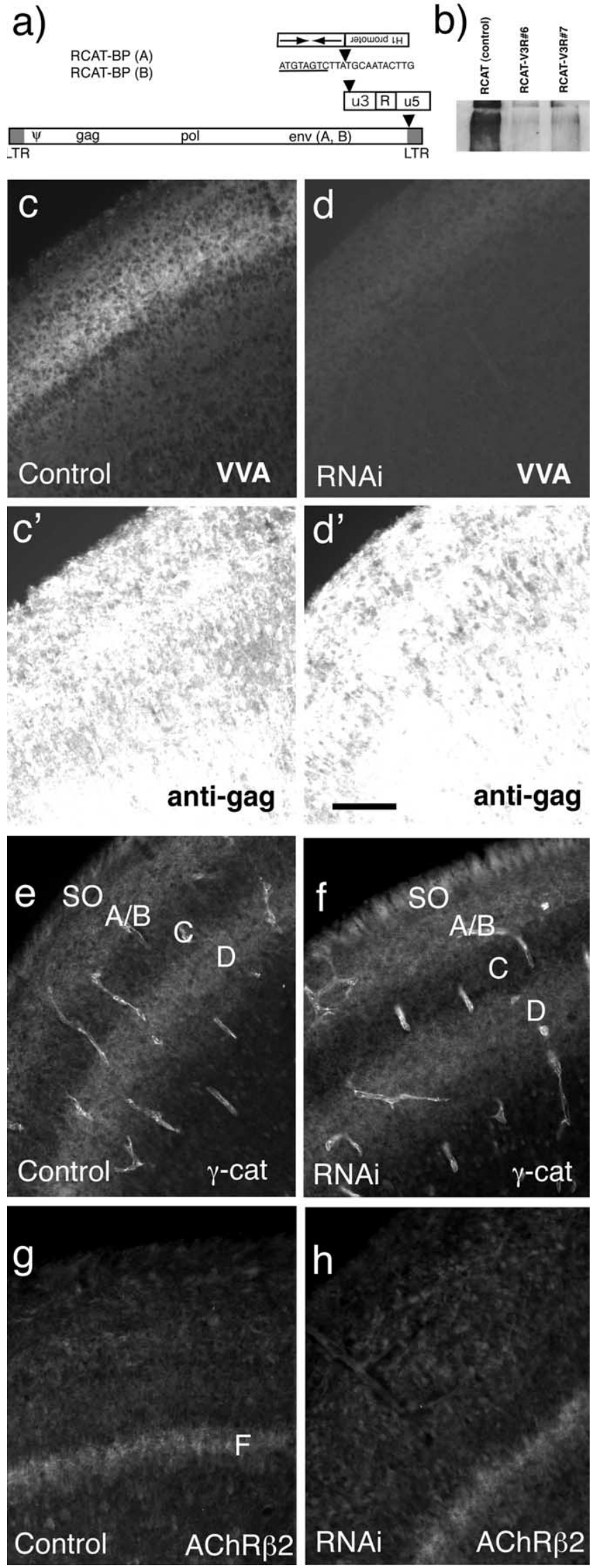

Figure 3. Suppression of versican expression by RNAi eliminates staining of the tectum by VVA. $\boldsymbol{a}$, Design of RCAT-BP retroviral vectors. See Materials and Methods for an explanation. u3, $\mathrm{R}$, and $\mathrm{u} 5$ are segments of the LTR; $g a g, p o l$, and env are retroviral genes. $\boldsymbol{b}$, Staining for VVA
Characterization of versican-expressing tectal cells

The tectal retinorecipient laminae comprise sublaminae stratum griseum et fibrosum superficiale (SGFS)-B, -C, -D, and -F (for nomenclature, see Yamagata et al., 1995). In situ hybridization showed that versican-positive cells were most numerous in SGFS-D/F, with declining numbers in $-\mathrm{C}$ and $-\mathrm{A} / \mathrm{B}$ (at E15, SGFS-A and -B are merged, as are SGFS-D and -F) and very few outside of the retinorecipient laminae (Figs. $2 b, 4 a$ ). Because the main versican-expressing cells described to date in mammalian brain are glia (Niederöst et al., 1999; Asher et al., 2002), we suspected that versican might mark a lamina-restricted glial subpopulation in the tectum. However, no versican-positive cells in the retinorecipient laminae were labeled by an antibody to the best available marker for the tectal glia glutamine synthetase (Linser and Moscona, 1981) (Fig. 4c). Moreover, the morphology of versican-positive cells (Fig. $4 c^{\prime}$ ) resembled that of horizontally oriented interneurons, which extend their processes parallel to tectal laminas (Hunt and Brecha, 1984). We therefore asked whether versican was expressed by neurons.

In studies to be reported elsewhere, we characterized three lamina-restricted neuronal subtypes in the retinorecipient laminae: reelin-positive neurons in the superficial portion of SGFS$\mathrm{A} / \mathrm{B}$, substance $\mathrm{P}$ receptor-positive neurons in the deeper portion of SGFS-A/B, and neuropilin-1-positive neurons in SGFS-D (M. Yamagata, J. A. Weiner, and J. R. Sanes, manuscript in preparation; Yamagata and Sanes, 1995b). The three markers are expressed in mutually exclusive neuronal subsets. Double-label in situ hybridization revealed that versican is expressed by some of the neurons that expressed each of these three markers (Fig. $4 d-$ $f$ ). Consistent with the gradient of versican expression, $\sim 80 \%$ of neuropilin-1-positive neurons in SGFS-D, $\sim 50 \%$ of substance $\mathrm{P}$ receptor-positive neurons in deep SGFS-A/B, and $\sim 5 \%$ of reelinpositive neurons in superficial SGFS-A/B were versican positive. Thus, versican is expressed in a graded, lamina-specific pattern by multiple neuronal subtypes (Fig. 4b).

\section{Effects of versican on RGC neurites}

Results presented so far indicate that retinal axons encounter versican when they enter the retinorecipient laminae of the tectum. To ask whether versican affects retinal axonal behavior, we used retinal explants. The only neurites that extend from such explants onto substrates coated with laminin plus poly-L-lysine are those of RGCs (Halfter et al., 1983). We could therefore ask how such neurites behaved when they encountered deposits of versican coated atop the laminin/polylysine. As a source of versican, we used a high-density proteoglycan fraction purified from the tectum at E14-E15 (Fig. 1b), a time at which RGC axons are actively arborizing in the tectum (Yamagata and Sanes, 1995a). Versican is the major component of this fraction, but smaller amounts of other proteoglycans may also be present.

In initial studies, we placed large $(>200 \mu \mathrm{m})$ spots of versican or BSA atop laminin/polylysine. Neurites growing on laminin/ polylysine crossed unimpeded onto BSA (Fig. $5 b$ ) but stopped at

\section{$\leftarrow$}

demonstrates depletion of the $\sim 500 \mathrm{kDa}$ versican species from tecta infected with the RNAi vector. Tecta were infected at E2 and analyzed at E17 as in Figure 1c. Results from one embryo infected with a control virus (RCAT) and two embryos infected with RNAi virus (RCAT-V3R\#6, RCAT-V3R\#7) are shown. $\boldsymbol{c}-\boldsymbol{h}$, Sections from control virus-infected $(\boldsymbol{c}, \boldsymbol{e}, \boldsymbol{g})$ and RNAi virusinfected $(\boldsymbol{d}, \boldsymbol{f}, \boldsymbol{h})$ tecta were stained with VVA $(\boldsymbol{c}, \boldsymbol{d})$, anti-gag $\left(\boldsymbol{c}^{\prime}, \boldsymbol{d}^{\prime}\right)$, anti- $\boldsymbol{\gamma}$-catenin ( $\gamma$-cat; $\boldsymbol{e}$, f) or anti-AChR- $\beta 2$. Gag staining shows that tecta were infected extensively. VVA stains versican-depleted tectum poorly, but tectal structure and location of $\gamma$-catenin- and AChR- $\beta 2$ positive retinal axons are not detectably perturbed. SO, Stratum opticum. Scale bar, $60 \mu \mathrm{m}$. 
borders where they encountered versican (Fig. 5a). This result confirms the repulsive or inhibitory effect of versican on neurite outgrowth reported previously (Schmalfeldt et al., 2000).

In cultures stained with antibodies to the synaptic vesicle component SV2, we observed accumulations of vesicle-rich puncta at versican borders (Fig. $5 c$ ). However, the extensive fasciculation of neurites at those borders made it impossible to determine whether vesicle clustering was a direct response to versican or a consequence of fasciculation. We therefore generated fields of smaller versican-rich spots ( 1-5 $\mu \mathrm{m}$ ) using a biolistic device (Kummer et al., 2002). Only a few neurites encountered each of these spots, so little fasciculation occurred. In such cultures, small SV2-rich puncta were distributed along neurites generally, but the largest SV2-rich puncta were found regularly at the perimeter of versican spots (Fig. $5 d, e$ ). Large accumulations were not observed at the perimeter of BSA-coated spots (data not shown). This result suggests that versican promotes formation or enlargement of vesicle-rich varicosities.

To quantify the effect of versican on vesicle aggregation, we generated patterns of alternating versican-rich and -poor stripes using the device described by Walter et al. (1987). As expected, neurites grew preferentially on laminin/polylysinecoated lanes. At intermediate versican levels, however, many neurites crossed onto the laminin/polylysine/versican-coated lanes. Large SV2-rich puncta $\left(>4 \mu \mathrm{m}^{2}\right)$ were $\sim 4$-fold more frequent on versicancontaining than on versican-free lanes (Fig. 5f,h), whereas the control protein had no effect on puncta size or number (Fig. $5 g, h$ ). Thus, in addition to exerting an inhibitory effect on neurite outgrowth, versican promotes clustering of synaptic vesicles, a key step in presynaptic maturation. Treatment of immobilized versican with chondroitinase $\mathrm{ABC}$ decreased its ability to promote vesicle clustering significantly and abolished its inhibitory effect on neurite growth, suggesting that the chondroitin sulfate chains are necessary for both activities but that they may not be sufficient for the vesicle clustering activity (data not shown).

\section{Versican promotes maturation of} retinal axonal arbors in vivo

To ask whether versican affects formation or maturation of retinal arbors in vivo, we suppressed versican production in tecta using the RNAi method described above. Retinorecipient laminae of both control
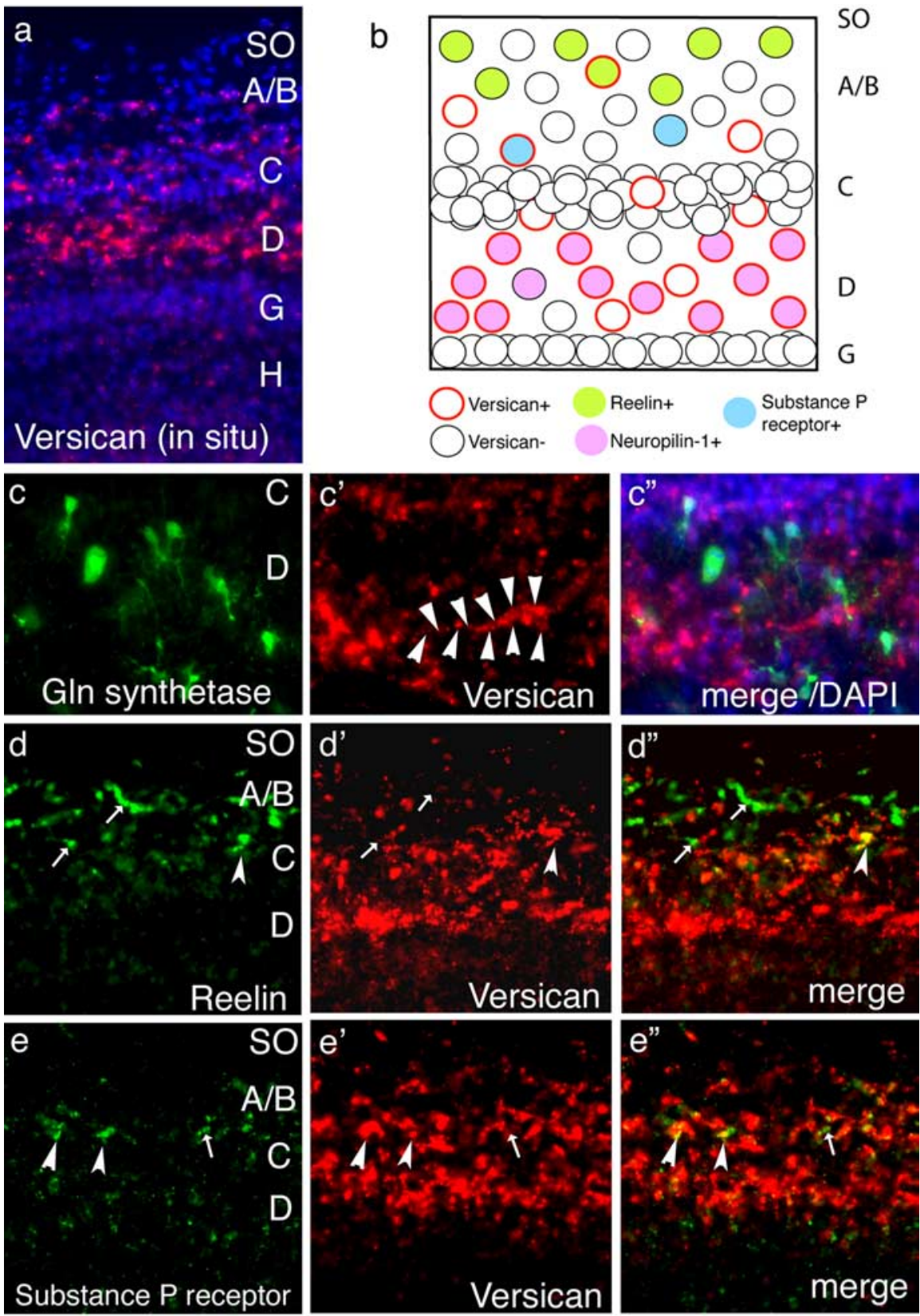

Substance $\mathrm{P}$ receptor
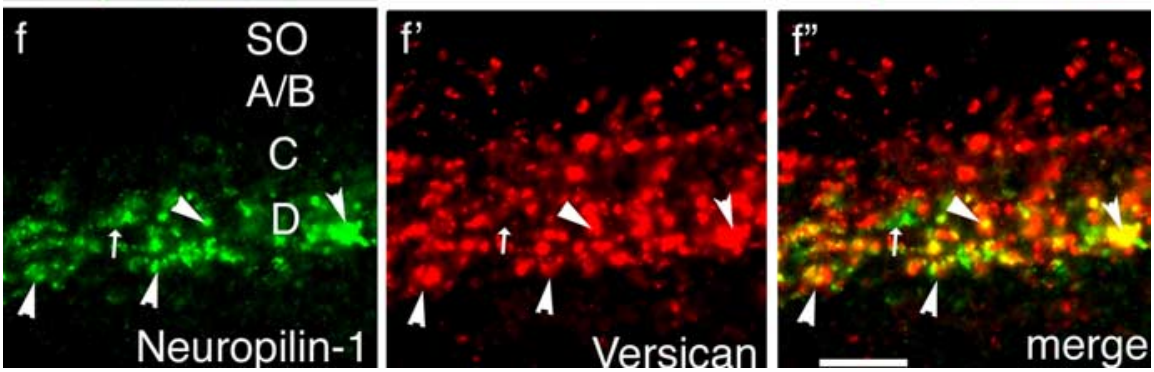

Figure 4. Characterization of versican-expressing cells in the retinorecipient laminae. E14 tectal sections were hybridized with probes for versican and counterstained as indicated. $\boldsymbol{a}$, DAPI staining shows nuclear localization. Versican is selectively expressed in the retinorecipient laminae (SGFS-A/B-D/F), with a gradient of expression from deep to superficial. $\boldsymbol{b}$, Diagram summarizing the results in $\mathbf{c}-\boldsymbol{f} . \boldsymbol{c}^{\prime} \boldsymbol{c}^{\prime}, \boldsymbol{c}^{\prime \prime}$, Anti-glutamine synthetase shows glia. Versican-positive cells are glutamine synthetase negative. $\boldsymbol{c}^{\prime}$, Horizontal processes of a versican-positive putative interneuron are indicated by arrowheads. $\boldsymbol{d}-\boldsymbol{f}$, In situ hybridization for markers of interneuronal subsets, reelin $\left(\boldsymbol{d}, \boldsymbol{d}^{\prime}, \boldsymbol{d}^{\prime \prime}\right)$, substance $\mathrm{P} \mathrm{receptor}\left(\boldsymbol{e}, \boldsymbol{e}^{\prime}, \boldsymbol{e}^{\prime \prime}\right)$, and neuropilin-1 $\left(\boldsymbol{f}, \boldsymbol{f}^{\prime}, \boldsymbol{f}^{\prime}\right)$. A fraction of each subset is versican positive. Versican-positive cells are indicated by arrowheads, and versican-negative cells are indicated by arrows. $\mathrm{SO}$, Stratum opticum. Scale bar, $20 \mu \mathrm{m}$. 

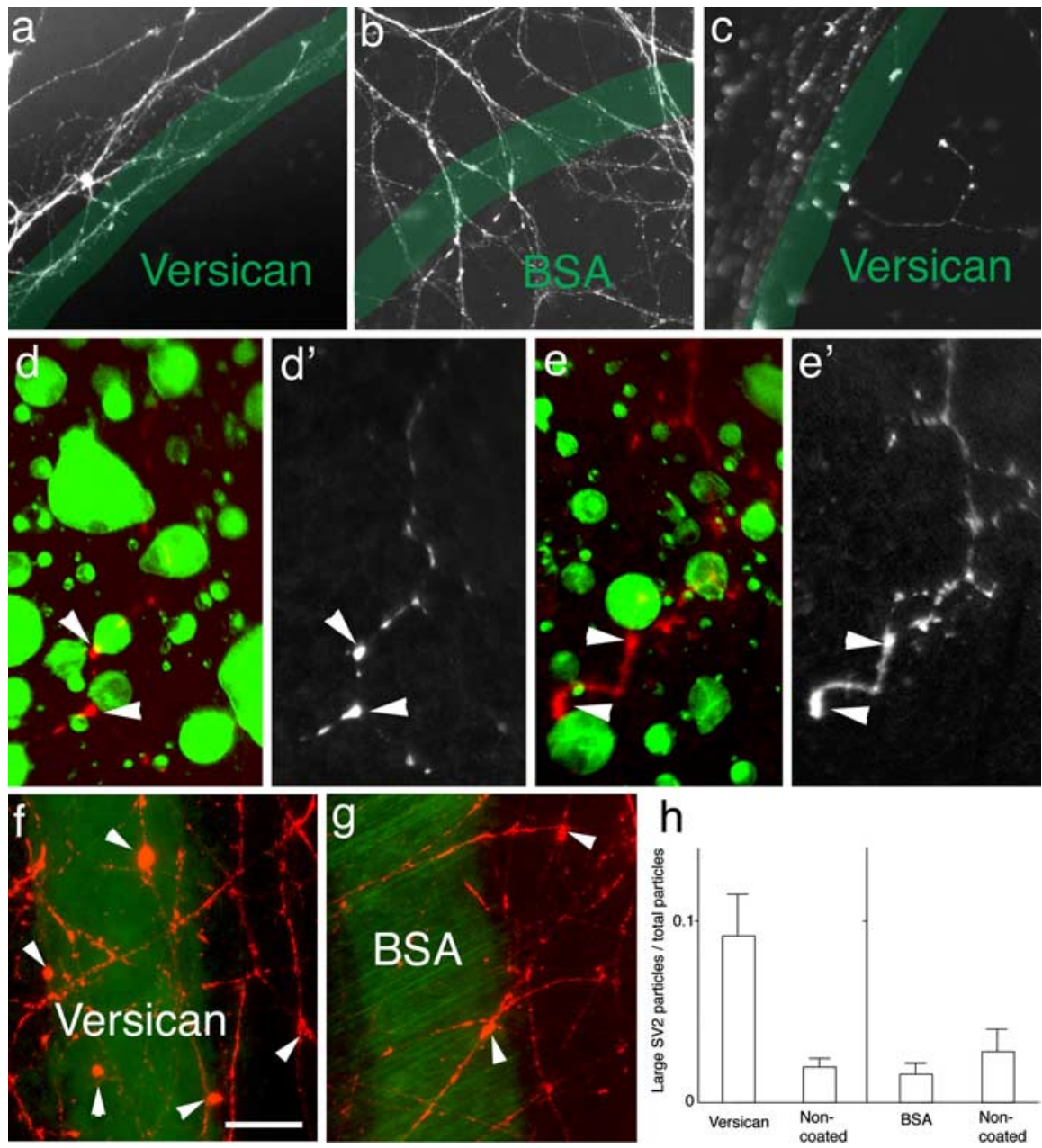

Figure 5. Versican induces formation of varicosities in retinal neurites. Retinal strips were plated on laminin; neurites extend ing from the strips encountered versican in large spots $(\boldsymbol{a}, \boldsymbol{c})$, small spots $(\boldsymbol{d}, \boldsymbol{e})$, or stripes $(\boldsymbol{f})$ or BSA in large spots $(\boldsymbol{b})$ or stripes $(\boldsymbol{g})$. Retinal strips were positioned above or to the left of the fields shown. The versican or BSA was mixed with fluorescein-BSA (green in $\boldsymbol{d}-\boldsymbol{f}$; border shown in green in $\boldsymbol{a}-\boldsymbol{c}$ ). Cultures were stained with anti-NgCAM to label neurites $(\boldsymbol{a}, \boldsymbol{b})$ or with SV2 to label synaptic vesicles $(\boldsymbol{c}-\boldsymbol{g}) . \boldsymbol{a}, \boldsymbol{b}$, Retinal neurites seldom cross onto areas of high versican density $(\boldsymbol{a})$ but cross unimpeded onto BSA (b). $\boldsymbol{c}$, Vesicle-rich varicosities form at the versican border. $\boldsymbol{d}, \boldsymbol{e}$, The largest SV2-rich varicosities (arrowheads) form at points of contact with versican ( $\boldsymbol{d}$ and $\boldsymbol{e}$ show neurites and versican; $\boldsymbol{d}^{\prime}$ and $\boldsymbol{e}^{\prime}$ show neurites only). $\boldsymbol{f}, \boldsymbol{g}$, Neurites crossed onto stripes of versican at low concentration $(\boldsymbol{f})$ or BSA $(\boldsymbol{g})$. $\boldsymbol{h}$, Large varicosities ( $>4 \mu \mathrm{m}^{2}$; arrowheads in $\boldsymbol{f}$ and $\boldsymbol{g}$ ) were more numerous on versican-coated stripes than on BSA- or laminin-coated stripes. Error bars indicated the mean \pm SEM from 18 fields. Scale bar: (in $\boldsymbol{f}$ ) $\boldsymbol{a}-\boldsymbol{c}, 4 \mu \mathrm{m}$; $d-g, 6 \mu \mathrm{m}$

and versican-depleted tecta were intensely stained by antibodies to markers of RGCs axons ( $\mathrm{Ng} / \mathrm{CAM}$, neurofilament $\mathrm{M}$, $\gamma$-catenin, and AChR- $\beta 2$ ) (Yamagata et al., 1995; Inoue and Sanes, 1997; Miskevich et al., 1998) (Fig. 3e,f and data not shown). Thus, versican is not essential for the entry of axons into the retinorecipient laminae. However, antibodies to two components of synaptic vesicles, SV2 and synaptotagmin, revealed that vesicle-rich puncta in retinorecipient laminae were smaller, on average, in versican-depleted than in control tecta, which had been treated with a virus that did not contain interfering RNA (Fig. 6a,b and data not shown). This effect is consistent with that seen in vitro and supports the idea that versican promotes presynaptic maturation.

To quantify the effect of versican on bouton size, we measured the size of puncta stained by anti-synaptotagmin, using computer-aided morphometric analysis of thresholded images (Fig. $\left.6 a^{\prime}, b^{\prime}\right)$. The density of large puncta $\left(>4 \mu \mathrm{m}^{2}\right)$ in versicandepleted tecta was $\sim 10 \%$ that in control tecta (Fig. $6 c$ ). The total number of puncta and the density of the smallest puncta $\left(<1 \mu \mathrm{m}^{2}\right)$ did not differ significantly between depleted and control tecta, consistent with a role for versican in varicosity growth.

Several results indicate that the role of versican in promoting formation or growth of varicosities is a specific one. First, analysis with multiple markers showed no effect of versican depletion on tectal development (Fig. 3 and data not shown). Second, even if some developmental retardation had occurred in the days before analysis at E17, it could not have accounted for the effect on varicosity size, because the density of large puncta $\left(>4 \mu \mathrm{m}^{2}\right)$ changed little between E14 and E18 in control tecta (Fig. $6 d$ ). Third, RNAi had no significant effect on puncta size in a non-retinorecipient lamina (SGFS-H) that contains little versican (Fig. 6e). Fourth, RNAi had no significant effect on the numbers of excitatory or inhibitory postsynaptic sites (stained with antiPSD-95 or anti-gephyrin, respectively) (Fig. $6 h, k$ ). Together, these results indicate a selective and local effect of versican on presynaptic maturation.

The effects of versican on the size of vesicle-rich puncta might reflect a decrease in vesicle density or a decrease in the size of the entire presynaptic varicosity. In either case, versican might affect retinal axons or synapses in the retinorecipient laminas derived from non-retinal inputs. To distinguish these alternatives, we analyzed retinal arbors that had been selectively impregnated by application of a lipophilic dye, DiI, to the optic tract (Yamagata and Sanes, 1995a). In controls analyzed at E17 (Fig. 7a,b), arbors are branched, confined to a single retinorecipient sublamina, and bear large varicosities that correspond to presynaptic profiles (see Discussion). Depletion of versican had no detectable effect on the complexity and laminar restriction of retinal arbors (Fig. $7 c, d$ and data not shown). In contrast, the number of varicosities per arbor was significantly decreased in versican-depleted tecta $(\sim 25 \%$; $p<0.01$ compared with control by $\chi^{2}$ test) (Fig. $7 e$ ), and the average diameter of varicosities was dramatically decreased $(>70 \%$ decrease in the number of varicosities with an area $>4 \mu \mathrm{m}^{2} ; p<0.001$ by $\chi^{2}$ ) (Fig. 7e). These results support the idea that versican promotes maturation of presynaptic specializations in retinal axons.

\section{Discussion}

\section{Versican as a laminar marker}

The initial descriptions of versican emphasized its expression by fibroblasts and abundance in connective tissue (for review, see Wight, 2002). Subsequent studies documented its presence in the developing and adult CNS (Milev et al., 1998; Schmalfeldt et al., 1998; Popp et al., 2003, 2004; Schweigreiter et al., 2004). In general, versican is believed to be synthesized primarily by glial cells 
(Niederöst et al., 1999; Asher et al., 2002) and to be expressed at higher levels in postnatal than in embryonic brain (Bignami et al., 1993; Milev et al., 1998). In the chick tectum, in contrast, versican is expressed primarily by neurons and at higher levels in mid-embryonic than in late embryonic stages.

Remarkably, versican is expressed by neurons confined to just a few of the 16 tectal laminae, the retinorecipient laminae (SGFS-B/F). In that sense, it is a laminar marker. Within the retinorecipient laminae, versican is expressed by a subset of interneurons that is heterogeneous in two respects. First, it is neurochemically diverse, including reelin-expressing neurons in SGFS-A/B, substance $P$ receptorexpressing neurons in SGFS-B, and neuropilin-1-expressing neurons in SGFS-D. In this respect, versican expression correlates better with laminar position per se than with a neurochemically defined interneuronal subtype. Second, the number of interneurons that express versican is graded within the retinorecipient laminas, from highest in SGFS-D/F to lowest in SGFS-A/B. This pattern raises the possibility that versican proteoglycan is also distributed in a graded manner, such that retinal axons penetrating the tectum grow "up" a gradient. Because high levels of versican inhibit neurite outgrowth, a graded distribution may help restrict retinal axons to the retinorecipient laminae and may also provide a way for axons to optimize the synaptogenic effects of the proteoglycan. Unfortunately, attempts to obtain direct evidence that versican proteoglycan distribution is graded have so far been unsuccessful. The monoclonal antibody that we used to detect versican in fibroblasts is known to recognize unrelated epitopes in tissue (Zako et al., 2002), and other antibodies we obtained were unsatisfactory for immunohistochemical staining (Yamagata, unpublished data). However, VVA staining strikingly supports the idea that versican proteoglycan is restricted to retinorecipient laminae in the tectum.

\section{Versican as a VVA ligand}

Several lines of evidence indicate that versican is the major tectal ligand recognized by the lectin VVA, which we showed previously to mark the retinorecipient laminae (Yamagata et al., 1995). First, versican is the major species purified from the tectum using VVA-agarose. Second, the selective staining of retinorecipient laminas by VVA is consistent with the selective expression of versican by interneurons in these laminae. Third, depletion of versican from the tectum by RNAi leads to a dramatic loss of VVA staining.

Although the evidence is strong that versican is a major VVA ligand, we cannot conclude that versican accounts for all of the VVA-binding material in the tectum. Other tectal proteoglycans may also bind VVA, although their patterns of expression, and loss of VVA staining after versican depletion, suggests that they are not major ligands. Instead, we suspect that these proteoglycans copurified with versican. At the neuromuscular junction, VVA binds to acetylcholinesterase (Scott et al., 1988), dystroglycan (McDearmon et al., 2001), and still-unidentified glycoproteins (Martin and Sanes, 1995; Martin et al., 1999) and glyolipids (Scott et al., 1988). Some of these may be present in the retinorecipient laminae as well.

Likewise, we do not conclude that all versican molecules in the tectum bind VVA. Versican is present in multiple, alternatively spliced forms and is heterogeneous in its glycosylation (Zako et al., 1997). Only some forms may bear the VVA-binding sugars. Such heterogeneity might account for difference between the graded expression of versican discussed above and the relatively lamina D-specific staining of retinorecipient laminas by VVA. An intriguing possibility is that a lamina-specific glycosylation mechanism (Scott et al., 1990; Li et al., 2000) selectively modifies a subset of versican core proteins. 

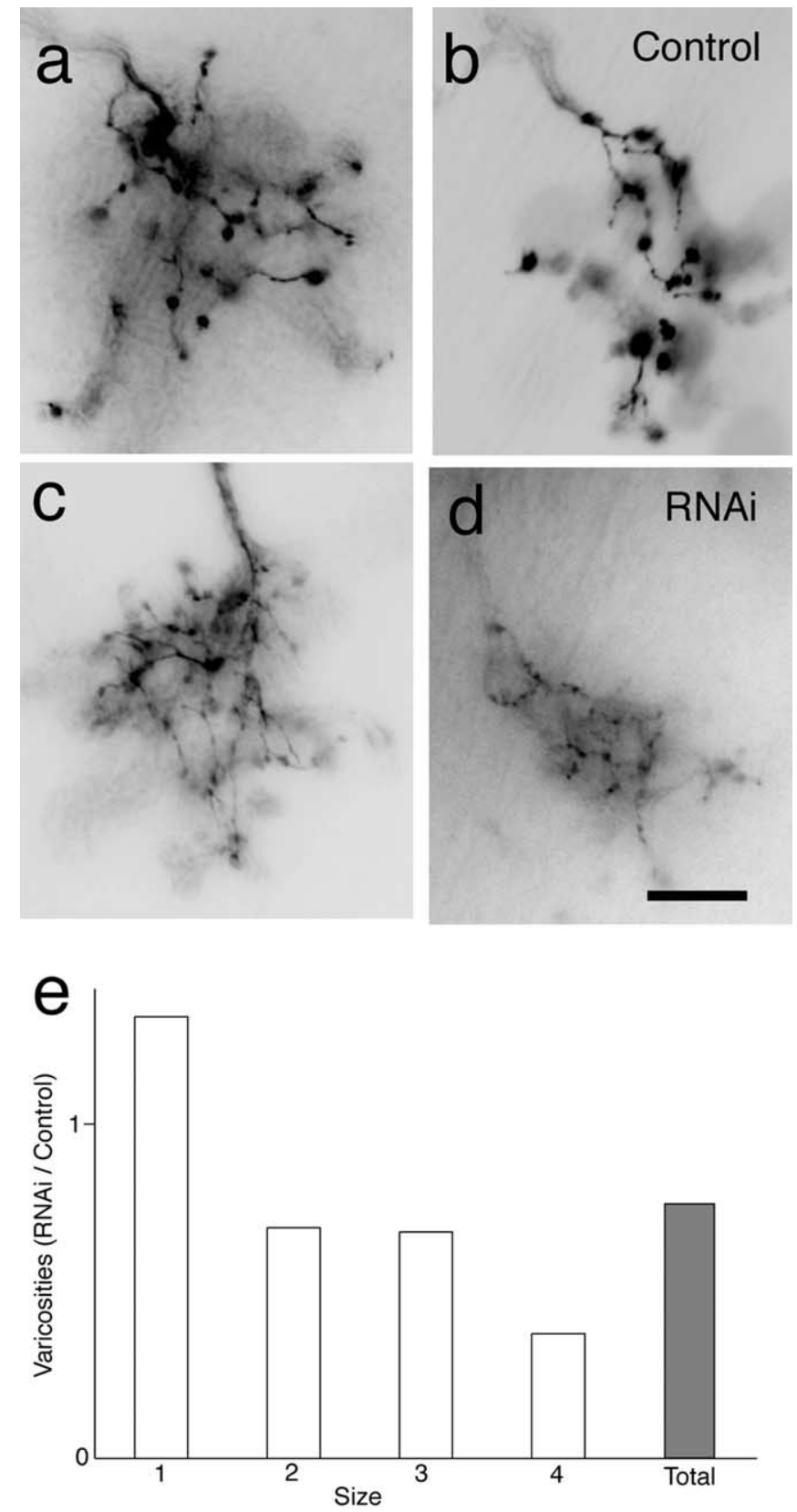

Figure 7. Perturbed differentiation of retinal arbors in versican-depleted tecta. Retinal arbors in tecta were impregnated by application of Dil to the optic tract. $\boldsymbol{a}-\boldsymbol{d}$ show examples, and e summarizes data from 14 arbors. Retinal arbors from RNAi-treated tecta $(\boldsymbol{c}, \boldsymbol{d})$ bore smaller varicosities than those from control tecta $(\boldsymbol{a}, \boldsymbol{b})$. The size classes are as in Figure $6 c$. The difference between control and RNAi arbors was significant at $p<0.001$ ( $\chi^{2}$ test). The total number of varicosities (gray bar in $\boldsymbol{e})$ is $\sim 25 \%$ lower in RNAi-treated than control arbors $\left(p<0.01 ; \chi^{2}\right.$ test). Scale bar, $3.3 \mu \mathrm{m}$.

\section{Versican as a regulator of synapse structure}

CSPGs, including versican, have been implicated in stabilization of synaptic connections in the maturing postnatal brain and in impeding regeneration after injury to the adult brain (see references in Introduction). Our results demonstrate a role for versican in an earlier aspect of neural development, the maturation of presynaptic structures. In vitro, large vesicle-rich varicosities formed at sites where neurites contacted versican. In vivo, selective elimination of versican led to reductions in the size of such varicosities. Correlative Golgi and electron microscopic studies have shown that the varicosities of retinal axons are variable in size; many are large (4-6 $\mu \mathrm{m}$ in the long dimension), glomerular in form, and contain multiple release sites (Hayes and Webster, 1975; Angaut and Repérant, 1976; Tömböl and Németh, 1999; Tömböl et al., 2003). The selective effect of versican on large varicosities might indicate that it plays a role in the transformation of simple into complex presynaptic structures. Although versican does not detectably affect postsynaptic structure in general (Fig. $6 f-k$ ), we do not know whether it affects the postsynaptic sites at synapses formed by retinal axons.

The effects we document in embryos may be related to the roles of CSPGs in synaptic stabilization. Lecticans, including versican, are principal components of perineuronal nets, which encapsulate neuronal somata and proximal dendrites (Celio et al., 1998; Yamaguchi, 2000; Matthews et al., 2002; Dityatev and Schachner, 2003). Based on their localization and development, perineuronal nets have been proposed to play an important role in the regulation of synaptic structures. Interestingly, GalNActerminated carbohydrates recognized by lectins such as VVA are characteristic components of perineuronal nets in the adult brain (Bertolotto et al., 1995; Ohyama and Ojima, 1997; Celio et al., 1998). We were unable to detect discrete perineuronal nets in embryonic chick tectum but speculate that the VVA-binding versican may play roles in embryos similar to those played by nets at later stages and may eventually coalesce into such nets.

How might versican control presynaptic development? Possibilities include the following. (1) Versican is anti-adhesive to many cell types (Yamagata et al., 1989, 1993b) and repels neurites (present study; Schmalfeldt et al., 2000) (but see Wu et al., 2004). Versican could concentrate presynaptic structures in discrete axonal segments by mechanical constriction, thereby leading to their expansion. (2) Versican bears multiple active sites that interact with a variety of receptors, including annexin 6, CD44, and integrins (Kawashima et al., 2000; Takagi et al., 2002; Wu et al., 2002), all of which are expressed in the nervous system. Such interactions activate signal transduction pathways (Zhang et al., 1998; Schweigreiter et al., 2004) that could lead to presynaptic differentiation. (3) Versican interacts not only with cells but also with other components of the ECM, including tenascin-R, link proteins, fibulin, and hyaluronan (Yamagata et al., 1986; Aspberg et al., 1997; Olin et al., 2001; Matsumoto et al., 2003). Presentation of these molecules might promote presynaptic differentiation.

In a previous study, we showed that application of VVA to tecta, in vivo or in vitro, inhibited arborization of retinal axons in the retinorecipient laminae (Inoue and Sanes, 1997). This result is related to but clearly distinct from the defect in presynaptic differentiation documented here after versican depletion. What could account for the difference? Based on data discussed above, possible reasons include the following. (1) Versican might interact with multiple receptors on neurons. Whereas versican knockdown would disrupt all such interactions, VVA might only disrupt a subset of them. (2) VVA may have tectal ligands other than versican. Thus, VVA may disrupt interactions of neurites with more than just versican. (3) Versican binds to and organizes multiple ECM components. Depletion of versican may secondarily lead to loss of these other components, whereas VVA treatment is unlikely to have this effect. (4) VVA has ligands on presynaptic as well as postsynaptic elements (Martin et al., 1999), so treatment with VVA might affect neurites directly as well as block their interactions with tectal ligands.

Although additional studies will be needed to distinguish these alternatives, it is noteworthy that a lamina-restricted ECM component and the lamina-restricted carbohydrate it presents 
act cooperatively to promote lamina-specific synapse formation as the tectum develops. Perhaps related molecular interactions between axons and their pericellular environment promote synaptic maturation during development and synaptic stability postnatally.

\section{References}

Angaut P, Repérant J (1976) Fine structure of the optic fibre termination layers in the pigeon optic tectum: a Golgi and electron microscope study. Neuroscience 1:93-105.

Asher RA, Morgenstern DA, Shearer MC, Adcock KH, Pesheva P, Fawcett JW (2002) Versican is upregulated in CNS injury and is a product of oligodendrocyte lineage cells. J Neurosci 22:2225-2236.

Aspberg A, Miura R, Bourdoulous S, Shimonaka M, Heinegard D, Schachner M, Ruoslahti E, Yamaguchi Y (1997) The C-type lectin domains of lecticans, a family of aggregating chondroitin sulfate proteoglycans, bind tenascin- $\mathrm{R}$ by protein-protein interactions independent of carbohydrate moiety. Proc Natl Acad Sci USA 94:10116-10121.

Bandtlow CE, Zimmermann DR (2000) Proteoglycans in the developing brain: new conceptual insights for old proteins. Physiol Rev 80:1267-1290.

Berardi N, Pizzorusso T, Maffei L (2004) Extracellular matrix and visual cortical plasticity: freeing the synapse. Neuron 44:905-908.

Bertolotto A, Manzardo E, Iudicello M, Lovisetto C, Riccio A (1995) Disappearance of the Vicia villosa-positivity from the perineuronal net containing chondroitin proteoglycan after chondroitinase digestion. Brain Res 673:344-348.

Bignami A, Perides G, Rahemtulla F (1993) Versican, a hyaluronatebinding proteoglycan of embryonal precartilaginous mesenchyma, is mainly expressed postnatally in rat brain. J Neurosci Res 34:97-106.

Bradbury EJ, Moon LDF, Popat RJ, King VR, Bennett GS, Patel PN, Fawcett JW, McMahon SB (2002) Chondroitinase ABC promotes functional recovery after spinal cord injury. Nature 416:636-640.

Brummelkamp TR, Bernards R, Agami R (2002) A system for stable expression of short interfering RNAs in mammalian cells. Science 296:550-553.

Caterson B, Christner JE, Baker JR, Couchman JR (1985) Production and characterization of monoclonal antibodies directed against connective tissue proteoglycans. Fed Proc 44:386-393.

Celio MR, Spreafico R, De Biasi S, Vitellaro-Zuccarello L (1998) Perineuronal nets: past and present. Trends Neurosci 21:510-515.

Dityatev A, Schachner M (2003) Extracellular matrix molecules and synaptic plasticity. Nat Rev Neurosci 4:456-468.

Drazba J, Lemmon V (1990) The role of cell adhesion molecules in neurite outgrowth on Müller cells. Dev Biol 138:82-93.

Hagihara K, Miura R, Kosaki R, Berglund E, Ranscht B, Yamaguchi Y (1999) Immunohistochemical evidence for the brevican-tenascin- $\mathrm{R}$ interaction: colocalization in perineuronal nets suggests a physiological role for the interaction in the adult rat brain. J Comp Neurol 410:256-264.

Halfter W, Newgreen DF, Sauter J, Schwarz U (1983) Oriented axon outgrowth from avian embryonic retinae in culture. Dev Biol 95:56-64.

Hascall VC, Calabro A, Midura RJ, Yanagishita M (1994) Isolation and characterization of proteoglycans. Methods Enzymol 230:390-417.

Hayes BP, Webster KE (1975) An electron microscope study of the retinoreceptive layers of the pigeon optic tectum. J Comp Neurol 162:447-465.

Herman JP, Victor JC, Sanes JR (1993) Developmentally regulated and spatially restricted antigens of radial glial cells. Dev Dyn 197:307-318.

Hockfield S, Kalb RG, Zaremba S, Frey H (1990) Expression of neural proteoglycans correlates with the acquisition of mature neuronal properties in the mammalian brain. Cold Spring Harbor Symp Quant Biol 55:505-514.

Homburger SA, Fekete DM (1996) High efficiency gene transfer into the embryonic chicken CNS using B-subgroup retroviruses. Dev Dyn 206:112-120.

Hughes SH, Greenhouse JJ, Petropoulos CJ, Sutrave P (1987) Adaptor plasmids simplify the insertion of foreign DNA into helper-independent retroviral vectors. J Virol 61:3004-3012.

Hunt SP, Brecha N (1984) The avian optic tectum: a synthesis of morphology and biochemistry. In: Comparative neurology of the optic tectum (Vanegas H, ed), pp 619-648. New York: Plenum.

Inoue A, Sanes JR (1997) Lamina-specific connectivity in the brain: regulation by $\mathrm{N}$-cadherin, neurotrophins, and glycoconjugates. Science 276:1428-1431.
Kawakami Y, Rodriguez-Leon J, Koth CM, Buscher D, Itoh T, Raya A, Ng JK, Esteban CR, Takahashi S, Henrique D, Schwarz MF, Asahara H, Izpisua Belmonte JC (2003) MKP3 mediates the cellular response to FGF8 signalling in the vertebrate limb. Nat Cell Biol 5:513-519.

Kawashima H, Hirose M, Hirose J, Nagakubo D, Plaas AH, Miyasaka M (2000) Binding of a large chondroitin sulfate/dermatan sulfate proteoglycan, versican, to L-selectin, P-selectin, and CD44. J Biol Chem 275:35448-35456.

Kimata K, Oike Y, Tani K, Shinomura T, Yamagata M, Uritani M, Suzuki S (1986) A large chondroitin sulfate proteoglycan (PG-M) synthesized before chondrogenesis in the limb bud of chick embryo. J Biol Chem 261:13517-13525.

Kummer TT, Nishimune H, Wong RO, Sanes JR (2002) Spotted substrates for focal presentation of proteins to cells. Biotechniques 33:1018-1020.

Li H, Leung TC, Hoffman S, Balsamo J, Lilien J (2000) Coordinate regulation of cadherin and integrin function by the chondroitin sulfate proteoglycan neurocan. J Cell Biol 149:1275-1288.

Linser PJ, Moscona AA (1981) Induction of glutamine synthetase in embryonic neural retina: its suppression by the gliatoxic agent alphaaminoadipic acid. Brain Res 227:103-119.

Margolis RK, Margolis RU (1993) Nervous-tissue proteoglycans. Experientia 49:429-446.

Martin PT, Sanes JR (1995) Role for a synapse-specific carbohydrate in agrin-induced clustering of acetylcholine receptors. Neuron 14:743-754.

Martin PT, Scott LJ, Porter BE, Sanes JR (1999) Distinct structures and functions of related pre- and postsynaptic carbohydrates at the mammalian neuromuscular junction. Mol Cell Neurosci 13:105-118.

Matsui F, Nishizuka M, Yasuda Y, Aono S, Watanabe E, Oohira A (1998) Occurrence of a N-terminal proteolytic fragment of neurocan, not a $\mathrm{C}$-terminal half, in a perineuronal net in the adult rat cerebrum. Brain Res 790:45-51.

Matsumoto K, Shionyu M, Go M, Shimizu K, Shinomura T, Kimata K, Watanabe H (2003) Distinct interaction of versican/PG-M with hyaluronan and link protein. J Biol Chem 278:41205-41212.

Matthews RT, Kelly GM, Zerillo CA, Gray G, Tiemeyer M, Hockfield S (2002) Aggrecan glycoforms contribute to the molecular heterogeneity of perineuronal nets. J Neurosci 22:7536-7547.

McDearmon EL, Combs AC, Ervasti JM (2001) Differential Vicia villosa agglutinin reactivity identifies three distinct dystroglycan complexes in skeletal muscle. J Biol Chem 276:35078-35086.

Milev P, Maurel P, Chiba A, Mevissen M, Popp S, Yamaguchi Y, Margolis RK, Margolis RU (1998) Differential regulation of expression of hyaluronan-binding proteoglycans in developing brain: aggrecan, versican, neurocan, and brevican. Biochem Biophys Res Commun 247:207-212.

Miskevich F (1999) Laminar redistribution of a glial subtype in the chick optic tectum. Dev Brain Res 115:103-109.

Miskevich F, Zhu Y, Ranscht B, Sanes JR (1998) Expression of multiple cadherins and catenins in the chick optic tectum. Mol Cell Neurosci $12: 240-255$.

Momose T, Tonegawa A, Takeuchi J, Ogawa H, Umesono K, Yasuda K (1999) Efficient targeting of gene expression in chick embryos by microelectroporation. Dev Growth Differ 41:335-344.

Moon LDF, Asher RA, Rhodes KE, Fawcett JW (2001) Regeneration of CNS axons back to their target following treatment of adult rat brain with chondroitinase ABC. Nat Neurosci 4:465-466.

Mumm SR, Grandgenett DP (1991) Defining nucleic acid-binding properties of avian retrovirus integrase by deletion analysis. J Virol 65:1160-1167.

Niederöst BP, Zimmermann DR, Schwab ME, Bandtlow CE (1999) Bovine CNS myelin contains neurite growth-inhibitory activity associated with chondroitin sulfate proteoglycans. J Neurosci 19:8979-8989.

Ohyama J, Ojima H (1997) Labeling of pyramidal and nonpyramidal neurons with lectin Vicia villosa during postnatal development of the guinea pig. J Comp Neurol 389:453-468.

Olin AI, Morgelin M, Sasaki T, Timpl R, Heinegard D, Aspberg A (2001) The proteoglycans aggrecan and versican form networks with fibulin-2 through their lectin domain binding. J Biol Chem 276:1253-1261.

Piller V, Piller F, Cartron JP (1990) Comparison of the carbohydratebinding specificities of seven $N$-acetyl-D-galactosamine-recognizing lectins. Eur J Biochem 191:461-466.

Pizzorusso T, Medini P, Berardi N, Chierzi S, Fawcett JW, Maffei L (2002) 
Reactivation of ocular dominance plasticity in the adult visual cortex. Science 298:1248-1251.

Popp S, Andersen JS, Maurel P, Margolis RU (2003) Localization of aggrecan and versican in the developing rat central nervous system. Dev Dyn 227:143-149.

Popp S, Maurel P, Andersen JS, Margolis RU (2004) Developmental changes of aggrecan, versican and neurocan in the retina and optic nerve. Exp Eye Res 79:351-356.

Rhodes KE, Fawcett JW (2004) Chondroitin sulphate proteoglycans: preventing plasticity or protecting the CNS? J Anat 204:33-48.

Sanes JR (1993) Basement membrane molecules in vertebrate nervous system. In: Molecular and cellular aspects of basement membranes (Rohrbach DH, Timpl R, eds), pp 189-210. New York: Academic.

Schmalfeldt M, Dours-Zimmermann MT, Winterhalter KH, Zimmermann DR (1998) Versican V2 is a major extracellular matrix component of the mature bovine brain. J Biol Chem 273:15758-15764.

Schmalfeldt M, Bandtlow CE, Dours-Zimmermann MT, Winterhalter KH, Zimmermann DR (2000) Brain derived versican V2 is a potent inhibitor of axonal growth. J Cell Sci 113:807-816.

Schwartz N (2000) Biosynthesis and regulation of expression of proteoglycans. Front Biosci 5:D649-655.

Schweigreiter R, Walmsley AR, Niederöst B, Zimmermann DR, Oertle T, Casademunt E, Frentzel S, Dechant G, Mir A, Bandtlow CE (2004) Versican V2 and the central inhibitory domain of Nogo-A inhibit neurite growth via p75NTR/NgR-independent pathways that converge at RhoA. Mol Cell Neurosci 27:163-174.

Scott LJ, Bacou F, Sanes JR (1988) A synapse-specific carbohydrate at the neuromuscular junction: association with both acetylcholinesterase and a glycolipid. J Neurosci 8:932-944.

Scott LJ, Balsamo J, Sanes JR, Lilien J (1990) Synaptic localization and neural regulation of an $\mathrm{N}$-acetylgalactosaminyl transferase in skeletal muscle. J Neurosci 10:346-350.

Shinomura T, Nishida Y, Ito K, Kimata K (1993) cDNA cloning of PG-M, a large chondroitin sulfate proteoglycan expressed during chondrogenesis in chick limb buds. Alternative spliced multiforms of PG-M and their relationships to versican. J Biol Chem 268:14461-14469.

Silver J, Miller JH (2004) Regeneration beyond the glial scar. Nat Rev Neurosci 5:146-156.

Takagi H, Asano Y, Yamakawa N, Matsumoto I, Kimata K (2002) Annexin 6 is a putative cell surface receptor for chondroitin sulfate chains. J Cell Sci 115:3309-3318.

Tömböl T, Németh A (1999) Direct connections between dendritic terminals of tectal ganglion cells and glutamate-positive terminals of presumed optic fibres in layers $4-5$ of the optic tectum of Gallus domesticus. A lightand electron microscopic study. Neurobiology 7:45-67.

Tömböl T, Eyre M, Zayats N, Németh A (2003) The ramifications and terminals of optic fibres in layers 2 and 3 of the avian optic tectum: a golgi and light and electron microscopic anterograde tracer study. Cells Tissues Organs 175:202-222.

Tropea D, Caleo M, Maffei L (2003) Synergistic effects of brain-derived neurotrophic factor and chondroitinase $\mathrm{ABC}$ on retinal fiber sprouting after denervation of the superior colliculus in adult rats. J Neurosci 23:7034-7044.

Walter J, Kern-Veits B, Huf J, Stolze B, Bonhoeffer F (1987) Recognition of position-specific properties of tectal cell membranes by retinal axons in vitro. Development 101:685-696.

Wight TN (2002) Versican: a versatile extracellular matrix proteoglycan in cell biology. Curr Opin Cell Biol 14:617-623.

Wu Y, Chen L, Zheng PS, Yang BB (2002) b1-Integrin-mediated glioma cell adhesion and free radical-induced apoptosis are regulated by binding to a C-terminal domain of PG-M/versican. J Biol Chem 277:12294-12301.

Wu Y, Sheng W, Chen L, Dong H, Lee V, Lu F, Wong CS, Lu WY, Yang BB (2004) Versican V1 isoform induces neuronal differentiation and promotes neurite outgrowth. Mol Biol Cell 15:2093-2104.

Yamagata M, Sanes JR (1995a) Lamina-specific cues guide outgrowth and arborization of retinal axons in the optic tectum. Development 121:189-200.

Yamagata M, Sanes JR (1995b) Target-independent diversification and target-specific projection of chemically defined retinal ganglion cell subsets. Development 121:3763-3776.

Yamagata M, Yamada KM, Yoneda M, Suzuki S, Kimata K (1986) Chondroitin sulfate proteoglycan (PG-M-like proteoglycan) is involved in the binding of hyaluronic acid to cellular fibronectin. J Biol Chem 261:13526-13535.

Yamagata M, Suzuki S, Akiyama SK, Yamada KM, Kimata K (1989) Regulation of cell-substrate adhesion by proteoglycans immobilized on extracellular substrates. J Biol Chem 264:8012-8018.

Yamagata M, Shinomura T, Kimata K (1993a) Tissue variation of two large chondroitin sulfate proteoglycans (PG-M/versican and PG-H/aggrecan) in chick embryos. Anat Embryol (Berl) 187:433-444.

Yamagata M, Saga S, Kato M, Bernfield M, Kimata K (1993b) Selective distributions of proteoglycans and their ligands in pericellular matrix of cultured fibroblasts. Implications for their roles in cell-substratum adhesion. J Cell Sci 106:55-65.

Yamagata M, Herman JP, Sanes JR (1995) Lamina-specific expression of adhesion molecules in developing chick optic tectum. J Neurosci 15:4556-4571.

Yamagata M, Weiner JA, Sanes JR (2002) Sidekicks: synaptic adhesion molecules that promote lamina-specific connectivity in the retina. Cell 110:649-660.

Yamaguchi Y (2000) Lecticans: organizers of the brain extracellular matrix. Cell Mol Life Sci 57:276-289.

Zako M, Shinomura T, Kimata K (1997) Alternative splicing of the unique "PLUS" domain of chicken PG-M/versican is developmentally regulated. J Biol Chem 272:9325-9331.

Zako M, Iwaki M, Yoneda M, Miyaishi O, Zhao J, Suzuki Y, Takeuchi M, Miyake G, Ikagawa H, Kimata K (2002) Molecular cloning and characterization of chick sialoprotein associated with cones and rods, a developmentally regulated glycoprotein of interphotoreceptor matrix. J Biol Chem 277:25592-25600.

Zhang Y, Cao L, Yang BL, Yang BB (1998) The G3 domain of versican enhances cell proliferation via epidermal growth factor-like motifs. J Biol Chem 273:21342-21351. 